\title{
Customer Relationship Management and the Performance of Selected Entrepreneurial Firms in Southwestern Nigeria
}

\author{
Akintunde Jonathan Oyedokun* Olamidayo Timi-Odeyemi \\ Department of Management and Accounting Ladoke Akintola \\ University of Technology, Ogbomoso, Nigeria
}

\begin{abstract}
Management of customers' vis-a- vis their needs and expectations has been a major challenge to entrepreneurs as they strife to maximise profit and increase their market share. Customer relationship management (CRM) thus serves as an essential avenue and component needed for the growth and sustainability of small-scale businesses. This article provides a description of CRM as a means of achieving customers satisfaction and sustaining firms' competitive position. A total of three hundred and eighteen (318) respondents participated in a survey of 45 registered medium scale entrepreneurial firms using purposive sampling across the states in south west Nigeria. Structural Equation Model was used to analyse the data. The findings revealed that information sharing with customers increases the trust and confidence customers have in firms. Long-term partnership between the companies and their customers through CRM demonstrates the level of trust, perseverance, and loyalty both enjoyed. Customer relationship management significantly influences the level of satisfaction derived by customers in companies' product, services, and activities.
\end{abstract}

Keywords: Customer Relationship Management, Structural Equation Model, Customers, Information sharing, Long Term Partnership, Customer Satisfaction.

DOI: $10.7176 / \mathrm{EJBM} / 13-3-04$

Publication date: January $31^{\text {st }} 2021$

\section{Introduction}

The ability of the small and medium scale entrepreneurial firms to leverage on a sound relationship management of their customers is a fundamental source of competitive advantage. Customer relationship management (CRM) help organizations achieve relevant knowledge about customers' preferences (Nazari-Shirkouhi., Keramati, and Rezaie, 2015). The knowledge then serves as a source of a highly effective and efficient tool to develop innovative capabilities. CRM is a process of customer interaction management needed to build, develop, and maintain long term beneficial relationships with customers, it thus becomes a strategic weapon for the sustainability of the business performance. Customer relationships are arguable the soul of business life (Rodriguez \& Honeycutt Jr, 2011) because it aimed at identifying, understanding, and cultivating customers in to fully determining their demands, tastes, and preferences. Understanding these concepts helps small and medium scale entrepreneurial firms develop and introduce product or services that best satisfy customers' needs. However, the management of customers vis-a- vis their needs and expectations has been a major challenge to entrepreneurs as they strife to maximise profit and increase their market share. The short life cycle of product and high turnover in technology has further increased business owners' worries and ability to hold on to their customers. The faster rate of changes occasioned by the demographic trends has further kept entrepreneurs and business owners alert and sensitive to latest demands and needs of their customers. Giving these enormous challenges, sustaining, and surpassing business competitive position thus requires a strong result-oriented CRM. This study therefore posits that CRM has a positive influence on the sustainability of the firms' competitive position in southwestern Nigeria.

\section{Literature Review}

The very essence of a business is its customers (Drucker, 1954), thus understanding customers' needs expectations and taste becomes imperative to keep the business running. One approach to sustain customers is by firms engaging themselves in a result-oriented CRM. Inherent benefits firms derived from a good CRM ranges from customers loyalty to user lead innovation through customers' feedback. Affirming this view, Ramani and kumar (2008) observed that CRM would help organizations achieve relevant knowledge about customers' preferences. CRM has also proved to be a highly effective and efficient tool to develop innovative capabilities and create competitive advantage within an organization (Ernst, Hoyer, Krafft, and Krieger, 2010).

Notwithstanding the enormous inherent benefit perceived in an organisation having a sound customers relationship management (CRM), a single individual barely has influence in achieving a result-oriented CRM however, every individual will be happy to be identified with the success whether he or she contributed to the achievement of a sound CRM or not. In Olson's words, nobody is ready to bear the expenses and sacrifice in achieving a sound CRM instead everyone is trying to profit from the benefit even in a greedy manner. 


\subsection{Conceptual clarification}

Providing customer satisfaction is continuously becoming the focused of every organization. However, meeting customers' expectations in the 21st century with various demand is far too challenging (Azzam, 2014); yet inevitable because customers are the best asset of an organization in modern day competitive world. Understanding the voice of the customers becomes essential to gain detail insights into customers' want and expectation. Customers' satisfaction can be perceived when an organization service quality (Wang, 2010) surpasses customers' expectations. Williams, Ashill, and Naumann (2017) also affirmed that customer satisfaction is the number of customers, or percentage of total customers, whose reported experience with a firm, its products, or its services exceeds specified satisfaction goals.

The satisfaction or dissatisfaction experienced by customers could spell boom or doom for a business in today's dynamic market driven by technology and social media. For instance, the power of reviews on socio media can seriously influence the business. Anderson, Swaminathan, and Mehta (2013) affirms that 49\% of consumers need at least 4 star ratings before choosing to use a business while $88 \%$ of consumers trust online reviews and personal recommendations to make decision on a business. Heller Baird and Parasnis (2011) also confirm that $72 \%$ of customers interact with brands that have positive reviews. Hence organization should consistently strive to satisfy customer to receive favourable feedback capable of maintaining customer loyalty. This implies that demonstration and attainment of sound customers satisfaction reflect an organization strong commitment to customers. Achieving this thus requires an effective strategic customer relationship management (CRM). CRM will help develop an informed idea of customers' expectations when they share their opinion and experiences about the company, its product, and services (Williams \& Naumann, 2011). Maintaining a sound CRM create and support customers networks, provide opportunity for customers to interact, identify and develop social relationships with the organization and other customers that can translate into greater loyalty toward the business and its brands. CRM becomes a comprehensive strategy needed to make customer satisfy, thus it creates value for the organization (Kakemam, Irani, Sokhanvar, Akbari, \& Dargahi, 2016). Customer satisfaction identified and met through CRM build trust, loyalty, and long-term relationship with customers (Mylonakis,2009).

\section{Methodology \\ 3.1 Study Area}

The study was conducted across five states (Ogun, Oyo, Osun, Ekiti, Ondo) in Southwest Nigeria. A total of 45 registered medium scale entrepreneurial firms constituted the study firms. The firms selected have been in business within a minimum of fifteen years and have a minimum of 30 employees excluding the founders. They are perceived to have witnessed significant growth amidst turbulences in their businesses as such their continuous survival is because of sustained customers' patronage. The firms were perceived appropriate for the empirical study and subsequent analysis.

\subsection{Samples and data collection}

The study initially made use of stratified sampling techniques to divide the population across three political zones in each state. Purposive sampling techniques was used to select firms in each state geopolitical zones spanning across their senatorial district. Three firms in each zone were purposively selected based on their ability to be registered companies that are active in business for a minimum of fifteen years and classified as small or medium scale entrepreneurial firms with a range of five to fifty employees. The stratification and the three numbers of selected firms across the zones in each state is to ensure equal representation. A total of three hundred and eighteen (318) respondents participated and responded to the administered questionnaires. Two hundred and seventy-four (274) questionnaires were received, connoting 86\% response rate. Following the data collection and screening exercise two hundred and fifty-five (255) questionnaires eventually made the analysis and discussions consisting 17 each across the purposively selected firms to ensure fair representation.

\subsection{Measures}

Customer relationship management has three constructs each having four factor loadings while small and medium scale firm's performances has two constructs having four factor loadings each. The use multiple measures are consistent with extant literatures (Covin and Slevin, 1989; Mc Doughall and Oviatt 2000; Wang, 2008; aimed at reducing measurement error and improving the statistical estimate of the relationship between the concept understudy (Hair et al., 2010). A total of five latent construct comprising 20 factor loadings was use for the analysis. 3.3.1 Customer Relationship Management

The concept customer relationship management (CRM) was perceived as a three higher order constructs namely: information sharing, long term partnership, and joint problem sharing. This is consistent with extant studies in literature (Mentzer, Min, and Zacharia 2000; Handfield and Bechtel 2002; McEvily and Marcus 2005; Aldaihani and Al-Hawary 2016) that perceived CRM as activities practiced by firms to satisfy customer needs through information sharing, joint problem sharing and solving and long-term partnership with customers. Respondents 
were asked to tick their choice on a 5point Likert scale statements relating to CRM.

\subsubsection{Information sharing}

Information sharing was perceived as sharing and exchange of essential and exclusive information through interactive activities between SME firm's and their customers (McEvily and Marcus, 2005; Mentzer et al., 2000; Lin, Chen, and Shun Chiu, 2009). The commonly shared information includes market demand, customer preferences, customers' expectations and complains, sales promotion, and new product introduction (Mentzer et al., 2000). Information sharing focusses on improving SME's performance through feedback received from customers. This is consistent with the works of Scandura and Ragins (1993), Taylor (2015) and Serrat (2017). Statements such as:

i. SME firms devoted special time listening to their customers complains and observations.

ii. Customers are free and encouraged to share their experiences and observations on new and existing products use.

iii. Feedback on how customers are treated are welcome without bias even when such feedbacks are not palatable.

iv. Messages are occasionally sent to customers expressing how valuable they are to their businesses as a means of appreciating them.

\subsubsection{Long Term Partnership}

Long term partnership was perceived as what a business does to build relationship with trust commitment and loyalty among its customers, business associate and business partners. Firms relationship with business partners are such that both firms honours their agreement and pursue similarly agreed business goals with deep sense of commitment. Trust easily comes to play when sharing the profit or loses that resulted from joint effort.

Statement such as:

i. We provide resources in a fair and dependable manner when we are involved in business dealings with our partners

ii. We often built trust with our partners through our total commitment to any joint business opportunities.

iii. We value and put in place key compliances and deadlines in business to nurture the mutual trust bestowed on us by our partners.

iv. We build stronger relationship by providing feedback on areas of partnership working well and core areas not working well with our partners

\subsubsection{Joint Problem Solving}

Joint problem-solving was conceived as the collaboration between customers, business partners and the firm in solving problems together and sharing responsibilities when they encounter difficult or unexpected situations (McEvily and Marcus, 2005). Joint problem solving is a cooperative approach that is focused on both parties optimizing their outcomes and growing and maintaining a long-term relationship. The customers or business partners can bring a considerable amount of skill and knowledge to the table. Statements capable of identifying joint problem solving were advance to capture the concept.

i. We offer result- oriented skills and knowledge when solving problems jointly with our partners or customers.

ii. We offer to share responsibilities with our customers or business partners when challenged with business difficulties.

iii. We engaged in meaningful discussion about best solutions to problems that will best meet, and not harm, the interests of our customers or partners.

iv. We are willing to work together and resolve problems with our partners or customers.

\subsubsection{Small and Medium Scale Performances}

The performance of small and medium scale businesses in the study area was measured using customers satisfaction (CS). CS is a measure of how products and services supplied by SME's meet or surpass customer expectation (Morgeson and Petrescu, 2011) and the number of customers whose reported experience with a firm, its products, or its services (ratings) exceeds specified satisfaction goals (Fornell, Rust and Dekimpe 2010), as such it becomes a key performance indicator within business (Pokryshevskaya, Elena, and Evgeny 2017). We measure CS with the level at which customers are happy with the company's responsiveness and resolution to customer concerns, problems, and complaint. This is premised on the assumption that responsive and sensitive firm keeps and maintain a happy, committed, loyal and satisfied customer. The willingness of customers to introduce or referred the product or services rendered to other customers is an indication of the level of trust confidence and satisfaction they derive from the firm's services or product. The convenience at which customers meet their needs effortlessly from a product or services of a firm reflects how satisfied they are with the firm processes

Model Specification

Following the construct specification, the measurement theory model tested was developed as indicated in figure 1. 


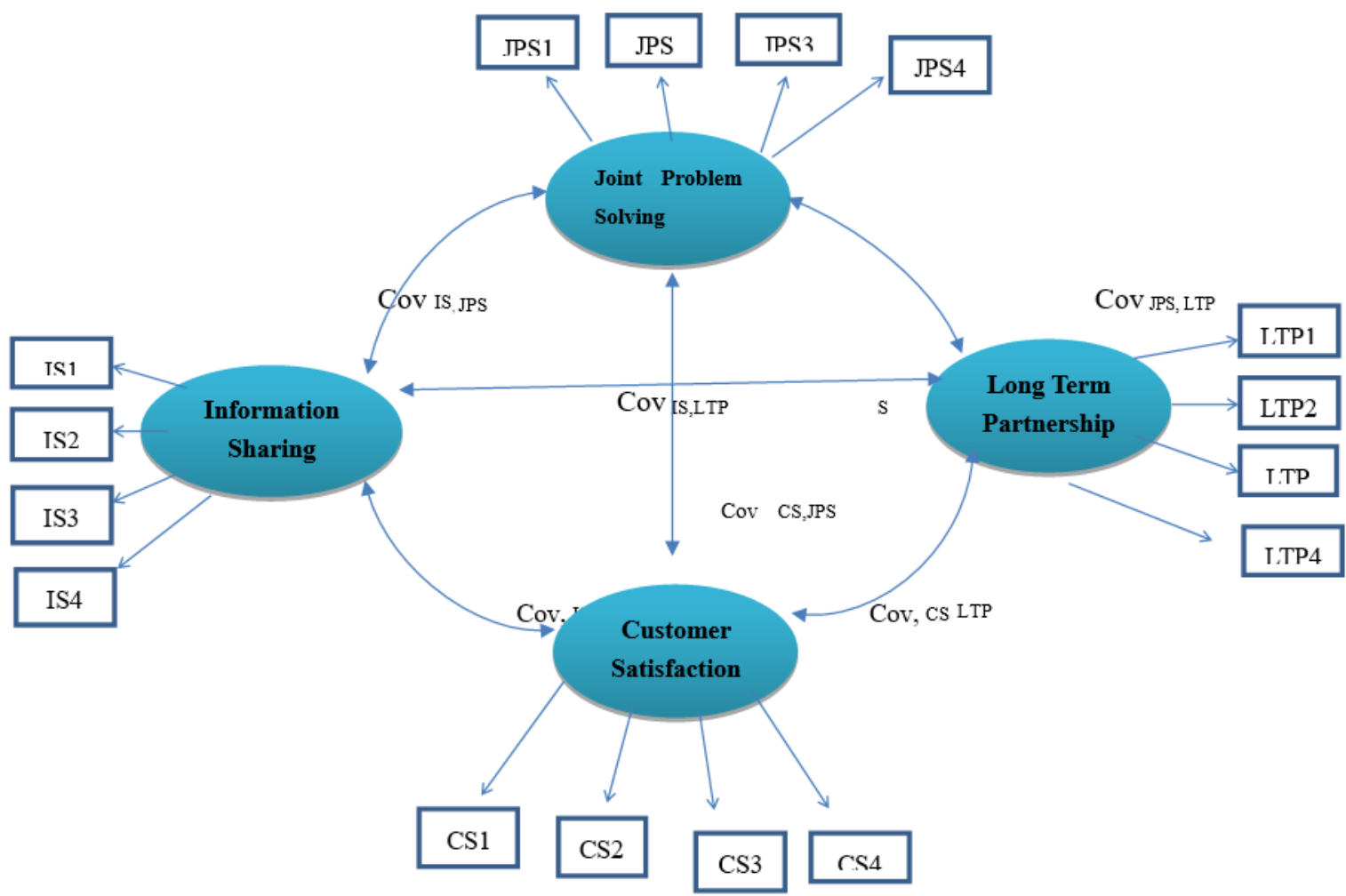

Figure 1: Measurement Model

The model displayed four latent constructs with sixteen measured indicators. The construct correlate with all other construct. The constructs were reflective in nature since they are based on the idea that the latent construct caused the measured variables and that error resulted to the inability to fully explain the measured variables (Hair et al.2010). The measured items loaded on only one construct. This is consistent with rules of unidimensional measures that a set of measured variables (indicators) can only be explained by one underlying construct (Ping 2004). The error terms are not also allowed to relate with any other measured variables. The measurement model is congeneric, and all construct are indicated by at least four major measured variables.

\subsection{Reliability and validity}

The study attempted to minimize measurement errors and bias by embarking on construct validity which requires the identification of a group of measurement items which were deemed to represent the construct in the study. Construct validity seeks to establish the extent to which the indicators measure the construct. Series of test to measure the properties of the indicators (Unidimensional, Reliability and Validity) were tested using confirmatory factors analysis. Reliability was assessed using Cronbach alpha. All construct measures (Information Sharing, Joint Problem Solving, Long Term Partnership, and Customer Satisfaction) met the recommended level of 0.70 and are therefore specified enough in their representative of the construct.

$\begin{array}{lcc}\text { Construct } & \text { Number of Indicators } & \text { Reliability } \\ \text { 1S } & 4 & 0.75 \\ \text { JPS } & 4 & 0.77 \\ \text { LTP } & 4 & 0.71 \\ \text { CS } & 4 & 0.82\end{array}$

Notes: IS= information Sharing; JPS=Joint Problem Solving, LTP=Long Term Partnership CS=Customer Satisfaction

\section{Analysis and Discussion of Results}

Confirmatory Factor Analysis and path relationship using structural equation model (SEM) was used in assessing and analysing the data. The model fit was assessed using normed chi-squarex ${ }^{\wedge} 2 / \mathrm{df}$, goodness of fit (GFI) and the comparative fit index (CFI). 12 items were included in the customer relationship management scale. Confirmatory factor analysis was performed with CRM as a higher order latent construct consisting four first order indicator. The measurement model resulted in a good fit order $\mathrm{X}^{\wedge} 2=118.57, \mathrm{df}=51, \mathrm{x}^{\wedge} 2 / \mathrm{df}=2.324, \mathrm{p}=0.001 . \mathrm{GFI}=0.951$, $\mathrm{CFI}=0.962$. The first order loadings ranged from 0.64 to $0.73(\mathrm{t}>1.96, \mathrm{p}<0.001)$. The second order loadings ranged from 0.59 to $0.84(\mathrm{t}>1.96, \mathrm{p}<0.001)$. 
Customer satisfaction construct was measured with 4 items. Confirmatory factor analysis was performed with Customer satisfaction. The measurement model resulted in a good fit $\mathrm{x}^{\wedge} 2=8.3, \mathrm{df}=2, \mathrm{x}^{\wedge} 2 / \mathrm{df}=4.15, \mathrm{p}=0.001$, $\mathrm{GFI}=0.912, \mathrm{CFI}=0.943$. The chi square statistics is significant and other relevant indices indicate a good overall fit (Tippins and Sohi, 2003).

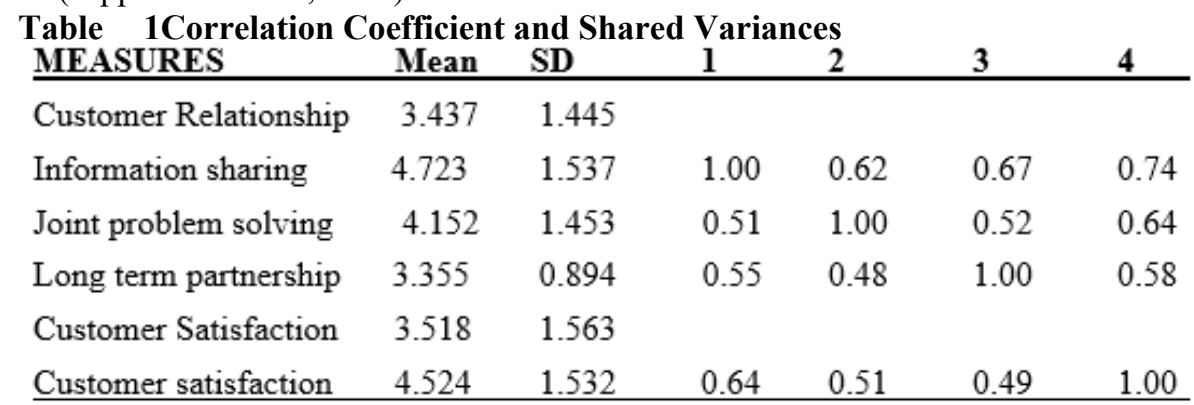

Note (1) Correlation Coefficient are reported in the upper diagonal half of the matrix and are significant at $\mathrm{p}<0.001$.(2) Shared variances are reported in the lower diagonal half of the matrix.

From the data obtained in table 1, the extent to which customer relationship management activities influences the satisfaction derived by customers was displayed on the table. The construct CRM was multidimensional using information sharing, joint problem solving and long-term partnership. Information sharing, joint problem solving, and long-term partnership respectively $(0.74,0.64,0.58)$ had a strong relationship customer satisfaction. This implies that the businesses are consistently exchanging or sharing basic and exclusive information through interactive activities with their customers and this actions have naturally endeared their customer to build trust in them and the feelings of being relevant also gives them a sense of belonging they ended up being satisfied by the companies activities, product and services because of the attitude of the firm that maintain constant rapport with the customers. This is consistent with the studies by McEvily and Marcus (2005) that information sharing with customers increases the trust and confidence customers have in a company's product or services. The company's effort aimed at striving to maintain communication flow alongside adequate feedback with customers boost the customers loyalty and satisfaction.

The strong relationship exhibited between joint problem solving and customer satisfaction was because of the cooperation between the company's and their customers in solving problems together and sharing responsibilities when facing difficult or unexpected market situations. The act of solving problem jointly had significant success on both the company's image and their customers confidence, it does reflect a win-win situation. Customers are not only well informed they were also participant in the processes as such they've never been in a limbo rather, they are key stakeholders as such they become naturally satisfied with the processes, they also played significant role to uphold while companies on the other hand keeps enjoying the customers loyalty, trust and satisfaction. A reflection of a strong image for the companies. This finding also aligns with the studies by Walter and Ritter (2003) that customer value is enhanced when they participated in the decision-making process. Lin and Germain (2004) also noted that organizations equipped with sound mechanisms for the participation of solving problems with the customer are in a better condition to provide after-sales services, meet customer needs, provide security and maintenance services. Maklan et al., 2008 that joint problem-solving help organization to understand the customer's needs deeply, with more value and reduce the risks in innovation.

Long term partnership and customer satisfaction also had a strong association. This reflects trust and commitment between the companies and their customers. The association is test of their perseverance and loyalty. This is an affirmation of a strong CRM that aligns with studies of Mohr and Spekman, (1994) that long-term partnership involves a high degree of commitment and mutual trust, that enable parties to provide resources in a fair and reliable way. The long-term partnership between the companies and their customers also concurred with the studies conducted by Sin et al., (2005) that long-term relationship builds and strengthen the objectives of mutual benefit with the company's goals and customer's satisfaction.

\section{Conclusion}

Customer relationship management is an essential tool not only needed to attain customer satisfaction, but also serves as an inherent mechanism needed to sustain the firm's competitive position. CRM promote information sharing with customers leading to mutual trust, confidence, and loyalty. CRM is an inevitable means of collaborating with customers, making them happy and giving them a sense of belonging. Through CRM, customers voice and feelings are heard as feedback.

\section{References}

Al-Hawary, S. I. S., \& Aldaihani, F. (2016). Customer relationship management and innovation capabilities of Kuwait Airways. International Journal of Academic Research in Economics and Management Sciences, 5(4), 
201-226.

Anderson, R. E., Swaminathan, S., \& Mehta, R. (2013). How to drive customer satisfaction. MIT Sloan Management Review, 54(4), 13.

Azzam, D. Z. A. M. (2014). The Impact of Customer Relationship Management on Customer Satisfaction in the Banking Industry. European Journal of Business and Management, (Online) Vol.6(No.32).

Covin, J. G., \& Slevin, D. P. (1989). Strategic management of small firms in hostile and benign environments. Strategic Management Journal, 10(1), 75-87.

Drucker, P. F. (1954). The practice of management: A study of the most important function in America society: Harper \& Brothers.

Ernst, H., Hoyer, W. D., Krafft, M., \& Krieger, K. (2010). Customer relationship management and company performance - the mediating role of new product performance. Journal of the Academy of Marketing Science, 39(2), 290-306. doi:10.1007/s11747-010-0194-5

Fornell, C., Rust, R. T., \& Dekimpe, M. G. (2010). The effect of customer satisfaction on consumer spending growth. Journal of Marketing Research, 47(1), 28-35.

Hair, J. F., Anderson, R. E., Babin, B. J., \& Black, W. C. (2010). Multivariate data analysis: A global perspective (Vol. 7). In: Upper Saddle River, NJ: Pearson.

Handfield, R. B., \& Bechtel, C. (2002). The role of trust and relationship structure in improving supply chain responsiveness. Industrial Marketing Management, 31(4), 367-382.

Heller Baird, C., \& Parasnis, G. (2011). From social media to social customer relationship management. Strategy \& Leadership, 39(5), 30-37. doi:10.1108/10878571111161507

Kakemam, E., Irani, A., Sokhanvar, M., Akbari, A., \& Dargahi, H. (2016). The relationship between organizational learning capabilities and job satisfaction in Tehran hospitals. Journal of Payavard Salamat, 9(5), 435-445.

Lin, R. J., Chen, R. H., \& Chiu, K. K. S. (2010). Customer relationship management and innovation capability: an empirical study. Industrial Management \& Data Systems.

Maklan, S., Knox, S., \& Ryals, L. (2008). New trends in innovation and customer relationship management: A challenge for market researchers. International Journal of Market Research, 50(2), 221-240.

McDougall, P. P., \& Oviatt, B. M. (2000). International entrepreneurship: the intersection of two research paths. Academy of management journal, 43(5), 902-906.

McEvily, B., \& Marcus, A. (2005). Embedded ties and the acquisition of competitive capabilities. Strategic Management Journal, 26(11), 1033-1055.

Mentzer, J. T., Min, S., \& Zacharia, Z. G. (2000). The nature of interfirm partnering in supply chain management. Journal of retailing, 76(4), 549-568.

Mohr, J., \& Spekman, R. (1994). Characteristics of partnership success: partnership attributes, communication behavior, and conflict resolution techniques. Strategic Management Journal, 15(2), 135-152.

Moore, J. H., \& Wang, Z. (2017). Mentoring Top Leadership Promotes Organizational Innovativeness through Psychological Safety and Is Moderated by Cognitive Adaptability. Frontiers in Psychology, 8(318). doi:10.3389/fpsyg.2017.00318

Morgeson, F. V., \& Petrescu, C. (2011). Do they all perform alike? An examination of perceived performance, citizen satisfaction and trust with US federal agencies. International Review of Administrative Sciences, 77(3), 451-479.

Mylonakis, J. (2009). Bank satisfaction factors and loyalty: a survey of the Greek bank customers. Innovative Marketing, 5(1), 16-25.

Nazari-Shirkouhi, S. (2015). Investigating the effects of customer relationship management and supplier relationship management on new product development. Tehnicki vjesnik - Technical Gazette, 22(1), 191-200. doi:10.17559/tv-20140623130536

Pokryshevskaya, E. B., \& Antipov, E. A. (2017). Profiling satisfied and dissatisfied hotel visitors using publicly available data from a booking platform. International Journal of Hospitality Management, 67, 1-10.

Ramani, G., \& Kumar, V. (2008). Interaction orientation and firm performance. Journal of marketing, $72(1), 27-$ 45.

Rodriguez, M., \& Honeycutt Jr, E. D. (2011). Customer relationship management (CRM)'s impact on B to B sales professionals' collaboration and sales performance. Journal of Business-to-Business Marketing, 18(4), 335356.

Scandura, T. A., \& Ragins, B. R. (1993). The effects of sex and gender role orientation on mentorship in maledominated occupations. Journal of vocational behavior, 43(3), 251-265.

Serrat, O. (2017). Harnessing creativity and innovation in the workplace. In Knowledge Solutions (pp. 903-910): Springer.

Taylor. (2015). Family Audi tGuidance And Mentorin. In.

Walter, A., \& Ritter, T. (2003). The influence of adaptations, trust, and commitment on value-creating functions of customer relationships. Journal of Business \& Industrial Marketing. 
Wang, C. L., \& practice. (2008). Entrepreneurial orientation, learning orientation, and firm performance. Entrepreneurship theory, 32(4), 635-657.

Williams, P., Ashill, N., \& Naumann, E. (2017). Toward a contingency theory of CRM adoption. Journal of Strategic Marketing, 25(5-6), 454-474.

Williams, P., \& Naumann, E. (2011). Customer satisfaction and business performance: a firm-level analysis. Journal of Services Marketing, 25(1), 20-32. doi:10.1108/08876041111107032 